\title{
DisCURSO ARGUMENTATIVO E PRODUÇÃO DE SENTIDOS EM INDIVÍDUOS COM SINDROME DE DOWN ${ }^{1}$
}

\author{
ARgumentative Discourse AND tHE PRODUCTION OF MEANING IN \\ INDIVIDUALS WITH DOWN SYNDROME
}

\author{
Tícia Cassiany Ferro CAVALCANTE²
}

\begin{abstract}
RESUMO: o presente estudo teve como objetivo identificar as características comunicativo-argumentativas em duas crianças com síndrome de Down, propondo-se analisar a produção de sentidos favorecida pelo discurso argumentativo em parceria com a pesquisadora. Para tal, a coleta de dados foi realizada em uma escola municipal do ensino fundamental I da cidade do Recife, com a participação de duas alunas com síndrome de Down. As alunas com síndrome de Down, individualmente, realizaram uma atividade discursiva com a intervenção da pesquisadora. As atividades individuais foram desenvolvidas com o auxílio de uma prancha, com o intuito de estabelecer a comunicação. Essas atividades tinham como tema assuntos do cotidiano das alunas que podiam ser passíveis de polemização. Os resultados demonstraram que as alunas com síndrome de Down parecem possuir especificidades discursivas na forma de argumentar. Em geral, os movimentos argumentativos realizados pelas alunas com síndrome de Down apareciam discursivamente na forma de gestos representativos e/ou verbalizações curtas - construções verticais.
\end{abstract}

PALAVRAS-CHAVE: Educação Especial. Argumentação. Impedimentos na Comunicação. Inclusão.

\begin{abstract}
The aim of this study was to identify communicative-argumentative characteristics in two children with Down Syndrome, to analyze the production of meaning assisted by argumentative discourse carried out with the researcher's help. To this end, data collection was carried out in a municipal primary school in the city of Recife, with the participation of students with Down Syndrome. The students with Down Syndrome carried out a discursive activity, individually, with the intervention of the researcher. The individual activities were performed with the help of a communication board, with the objective of establishing communication. These activities dealt with day-to-day topics related to the students' lives, which could be turned into polemic issues and discussion. The results demonstrated that students with Down Syndrome seem to posses discursive specificities in the way of argumentation. In general, the argumentative processes carried out by the students with Down Syndrome appeared discursively in the form of representative gestures and/or short verbalizations - vertical constructions.
\end{abstract}

KEYWORDS: Special Education. Argumentation. Communication impediments. Inclusion.

\section{INTRODUÇÃo}

O presente artigo tem foco no discurso argumentativo, dentro de uma tradição dos estudos em Psicologia que buscam entender o papel da argumentação na constituição do conhecimento e produção de sentidos (LEITÃO, 2003, 2000a,

\footnotetext{
1 Agradecimento a FACEPE pela concessão de bolsa de Iniciação Científica. Agradecimento, também, as contribuições das alunas Danila Melo, Juliana Aparecida Alves e Gleice Costa.

${ }^{2}$ Professora Adjunta do Departamento de Psicologia e Orientação Educacionais, Centro de Educação, UFPE. ticiaferro@hotmail.com
} 
1999; LEITÃO, DE CHIARO, 2005). Contudo, existe uma especificidade no estudo aqui reportado: foi realizado com pessoas com síndrome de Down e que possuem impedimentos na comunicação. Nesta mesma direção, Cavalcante e Santa-Clara (no prelo) procuraram analisar como o engajamento em práticas argumentativas pode favorecer o desenvolvimento da comunicação em crianças com síndrome de Down. Para as autoras, a argumentação se institui como um importante artefato para o processo de ensino e aprendizagem na educação inclusiva, pois permite que os pares em interação, pessoas com deficiência ou não, negociem e construam conhecimentos partilhados, levando-os a participar ativamente nas atividades comunicativas. $\mathrm{O}$ ambiente argumentativo implementado pelas pesquisadoras possibilitou/estimulou o desenvolvimento da comunicação dos participantes, na medida em que os impeliu à produção de movimentos argumentativos e à tomada de decisões.

Em consonância com a pesquisa supracitada, o presente estudo teve como objetivo identificar as características comunicativo-argumentativas em duas crianças com síndrome de Down, propondo-se analisar a produção de sentidos favorecida pelo discurso argumentativo em parceria com a pesquisadora. Tem-se a hipótese de que os impedimentos linguísticos decorrentes da síndrome de Down não inviabilizam o desenvolvimento da comunicação em situações argumentativas, ao se pensar na valorização das peculiaridades linguísticas de tais indivíduos.

A relevância do presente estudo remete a possibilidade de garantia da acessibilidade das pessoas com impedimentos comunicativos, podendo permitir a superação das barreiras comunicacionais. Tais barreiras estão presentes de forma sistemática no cotidiano da escola, em que os professores em suas práticas pedagógicas parecem relegar a segundo plano os alunos que não tem fluência oral. Alguns autores defendem que a escola acaba por segregar os alunos com deficiência por existir a valorização da comunicação oral em detrimento de outras formas de comunicação (FERREIRA; FERREIRA; OLIVEIRA, 2010) e por subestimar as potencialidades e possibilidades de desenvolvimento dos indivíduos com deficiência de ordem intelectual (PINTO; GÓES, 2006). Na concepção de alguns professores, o aluno que não consegue fazer uso da linguagem oral, seja parcial ou totalmente, não é capaz de aprender. Romper os estigmas, compreender o funcionamento e as características da síndrome, como ponto de partida, parece favorecer a prática social e pedagógica, permitindo acessibilidade.

Clinicamente a Síndrome de Down é caracterizada por um erro na distribuição dos cromossomos nas células. É uma cromossomopatia, ou seja, uma síndrome cujo quadro clínico global deve ser explicado por um desequilíbrio na constituição cromossômica (VOIVODIC, 2004). Na maioria dos casos, tal desequilíbrio caracteriza-se por um cromossomo extra no par 21, totalizando 47 cromossomos (em todas as células). Assim, há uma alteração na divisão cromossômica usual, resultando numa triplicação - ao invés de uma duplicação do material genético referente ao cromossomo 21. 
Em decorrência das alterações genéticas, os indivíduos com síndrome de Down possuem impedimentos na comunicação decorrente, principalmente da deficiência intelectual (VOIVODIC, 2004; LIMONGI, 2004; PUESCHEL, 2006 STRAY-GUNDERSEIN, 2007). Neste campo, uma característica importante que é mencionada por vários pesquisadores é o descompasso entre a produção e a compreensão de linguagem verbal (LIMONGI, 2004; PUESCHEL, 2006). Dessa forma, a compreensão da linguagem é mais preservada quando comparada a produção/expressão.

Apesar dos impedimentos comunicacionais, Voivodic (2004) defende que a maioria das crianças com síndrome de Down faz uso funcional da linguagem e compreende as regras utilizadas na conversação, mesmo que as habilidades comunicativas sejam bastante variadas entre elas.

Dentro de uma perspectiva da neurociência, que prioriza o conceito de plasticidade, Silva e Kleinhans (2006) mencionam que esses indivíduos, mesmo tendo impedimentos em decorrência de uma alteração genética, possuem uma capacidade espetacular de se adaptar ao meio. Assim, a concepção de plasticidade cerebral, implica considerar o ecossistema no qual o indivíduo está inserido, ou seja, o desenvolvimento do sujeito está diretamente relacionado com a qualidade, duração e forma de estimulação que recebem. As referidas autoras enfatizam que se um trabalho de estimulação dos processos cognitivos for realizado de maneira adequada, nos primeiros anos de vida, poderá promover significativas modificações no desenvolvimento. Enfatiza-se que tal estimulação é importante para qualquer criança, sem ou com deficiência.

Infelizmente, durante muito tempo, como destaca Voivodic (2004), a Síndrome de Down foi associada à condição de inferioridade, principalmente sob a influência do modelo médico de deficiência. Esse modelo buscava prover ao deficiente a assistência em serviço especializado, o que não lhe propiciava desenvolvimento pessoal, social, educacional e profissional plenos. Assim, para a referida autora é a própria sociedade que cria problemas para a pessoa com deficiência intelectual, colocando-a em desvantagem para desempenhar suas funções em virtude de ambientes restritivos e discriminatórios.

Ao mudar atitudes e concepções acerca das pessoas com deficiência, podese considerar que todas as pessoas (com deficiência ou não) fazem adaptações peculiares ao meio a depender dos seus impedimentos. No caso das pessoas com síndrome de Down, para compensar os impedimentos na comunicação, elas, em geral, desenvolvem de modo significativo a comunicação gestual, com o objetivo de se fazerem melhor compreendidas. Dessa maneira, as palavras expressas verbalmente parecem desempenhar um papel secundário na comunicação. De acordo com Porto-Cunha e Limongi (2008), os gestos constituem-se para as pessoas com síndrome de Down em um meio mais confiável e fácil de comunicação. 
No entanto, como já mencionado, elas acabam sendo segregadas, principalmente por ser a linguagem verbal a forma de comunicação mais valorizada nas instituições sociais - contempla a maioria linguística.

O paradigma de inclusão defende que a sociedade passe a valorizar e respeitar qualquer forma de comunicação humana, não atribuindo status a linguagem/comunicação verbal em detrimento de outras formas, como gestos, língua de sinais, dentre outros.

Nesta direção, a Convenção sobre os Direitos da Pessoa com Deficiência (CONVENÇÃO..., 2006) conceitua comunicação:

[...] abrange as línguas, a visualização de textos, o braile, a comunicação tátil, os caracteres ampliados, os dispositivos de multimídia acessível, assim como a linguagem simples, escrita e oral, os sistemas auditivos e os meios de voz digitalizada e os modos, meios e formatos aumentativos e alternativos de comunicação, inclusive a tecnologia da informação e comunicação (art. 2. Definições).

Como se percebe a Convenção sobre os Direitos da Pessoa com Deficiência amplia o conceito de comunicação ao colocar no mesmo patamar da verbal outras formas de comunicação. Desta forma, para permitir a diminuição das barreiras comunicacionais das pessoas que tem deficiência é importante que sejam utilizados de recursos de acessibilidade, a exemplo dos sistemas de Comunicação Aumentativa e Alternativa (CAA).

Para Paula e Enumo (2007), diferentes meios de comunicação derivados do uso de gestos, linguagem de sinais e expressões faciais, figuras, símbolos, além de sofisticados sistemas computadorizados podem ser empregados de forma substitutiva ou suplementar de apoio à fala, ajudando a desenvolver, quando possível, a linguagem oral.

Para a aquisição e generalização de habilidades de comunicação alternativa por indivíduos com impedimentos linguísticos propõe-se que sejam executadas mudanças sistemáticas nos ambientes sociais nos quais eles estão inseridos.

A atividade utilizada na presente pesquisa, para atender as peculiaridades linguísticas das crianças, foi composta por artefatos de apoio a comunicação: pranchas de comunicação. Além disso, ressalta-se aqui que para analisar a comunicação das crianças com síndrome de Down, foram utilizados os conceitos trazidos por Tetzchner e Martinsen (2000) de construções verbais verticais e horizontais. O conceito de estruturas horizontais e verticais relaciona-se à construção de frases: de um só elemento, no caso de construções verticais e; de mais elementos, para as construções horizontais.

Os referidos autores relatam que as pessoas que necessitam de um meio de expressão para se comunicarem, utilizam por mais tempo do que as crianças sem deficiência de frases de uma só palavra (construções verticais). Eles enfatizam ainda que a participação dessas crianças em interações sociais é marcada por 
dificuldades, pois as mesmas demoram mais tempo do que as crianças sem deficiência a processar e reagir aos estímulos recebidos. Muitas vezes, o adulto acaba controlando a interação pelo fato das crianças apresentarem um nível baixo de atividade. Esse controle e a não garantia da autonomia e independência das pessoas com síndrome de Down, acabam por levá-las a serem dependentes da ajuda, ficando incapazes de usar as suas capacidades de forma espontânea.

Na perspectiva de intervenção em CAA, os enunciados com uma estrutura vertical podem facilitar a comunicação, na medida em que os pais e demais adultos podem ajudar a formar enunciados deste tipo.

Parte-se, aqui, do pressuposto de que as crianças com síndrome de Down possuem peculiaridades comunicativas caracterizadas por utilização, demasiada, de gestos e construções verticais. Neste sentido, os impedimentos comunicativos dessas crianças não inviabilizam o desenvolvimento da comunicação (produção de sentidos). Assim, propõe-se investigar aqui as características comunicativoargumentativas dessas crianças.

Leitão $(2003$, 1999) define a argumentação como atividade de natureza discursiva que se realiza pela justificação de pontos de vistas e consideração de objeções (contra-argumentos), com o objetivo último de tornar as posições defendidas aceitáveis. A justificação de pontos de vista e a consideração de ideias alternativas, tomadas em conjunto, criam no discurso um espaço de negociação, no qual perspectivas a respeito do mundo (físico ou social) são continuamente formuladas, revistas e transformadas. Portanto, o processo de negociação de perspectivas é crucial à argumentação, pois permite construção, avaliação e reconstrução de sentidos, consequentemente, a construção de conhecimento natureza epistêmica.

Adota-se, aqui, a proposta de Leitão (2000b) que propôs uma unidade de análise triádica, composta de argumento, contra-argumento e resposta. $\mathrm{O}$ argumento é formado por ponto de vista e justificativa para o ponto de vista. $\mathrm{O}$ segundo elemento, contra-argumento, consiste em qualquer ideia produzida pelo próprio falante ou por um oponente com a qual se desafia o ponto de vista. E o terceiro elemento é a resposta ou reação ao contra-argumento, o qual permite que se acompanhe a transformação na perspectiva dos indivíduos.

Ela confere ao contra-argumento um papel crucial na construção de conhecimento e produção de sentidos, visto que é por meio do contra-argumento que o interlocutor testa seu ponto de vista - existe aí a negociação de perspectivas, que favorece o processo de revisão de uma perspectiva velha para uma nova perspectiva do tópico.

A resposta ao contra-argumento é o elemento da argumentação que reflete a consideração de ideias favoráveis ou desfavoráveis sobre dado assunto. Segundo Leitão (2000b), a resposta ao contra-argumento pode configurar-se de quatro formas, com ou sem ajuste na perspectiva assumida inicialmente pelo interlocutor 
(ponto de vista), que permite capturar as transformações. É a reação imediata ou remota do falante a contra-argumentos levantados. A identificação da reação do argumentador a perspectivas contrárias é vista aqui como um elemento crítico para a análise de processos de produção de sentido, foco do presente estudo, que têm lugar na argumentação.

\section{Método}

A pesquisa relatada em seguida se caracteriza como dois estudos de caso, realizados nas dependências de uma escola municipal da cidade do Recife. Participaram da pesquisa duas crianças com síndrome de Down, do ensino fundamental I, alunas de uma sala de aula regular. A coleta de dados foi realizada em uma atividade individual entre pesquisadora-aluna.

Assim, foram planejadas e elaboradas duas situações, com temas específicos, uma para cada participante da pesquisa. As temáticas utilizadas partiam de situações que estavam ligadas à realidade dos alunos, a saber: merenda escolar e programas de televisão.

O planejamento e elaboração das atividades exigiam que a pesquisadora tornasse o tema escolhido polemizável, bem como que pensasse nos impedimentos comunicativos das participantes. Neste sentido, a pesquisadora elaborou uma prancha de CAA para que as alunas participantes pudessem construir a proposta e desenvolver a comunicabilidade. A prancha de comunicação foi constituída de cartolina, para que as crianças fossem colocando os cartões por elas selecionados. É importante salientar que as alunas, na prática pedagógica cotidiana, não utilizam de ferramentas de CAA.

A situação de pesquisa constava de uma atividade de aproximadamente 30 minutos em que foi construída apenas uma prancha temática por participante. A prancha foi dividida, com uma linha central (duas partes) para que a aluna colocasse sua opinião a respeito do tema, já que existiam duas alternativas possíveis (negativa e positiva). Os cartões, em que constava uma figura e a palavra representativa da figura, consistiam de conteúdos que faziam parte do cotidiano das alunas. No caso da merenda escolar, os cartões correspondiam a comidas que fazem parte do cardápio da escola, a exemplo de iorgute, sucos, frutas. Assim, a aluna tinha que, a partir da apresentação dos cartões, selecionar os que ela achava que deveria ter na merenda, como a utilização do critério "gostar ou não gostar". No caso dos programas de televisão, a dinâmica era a mesma, a aluna deveria escolher dentre os programas aqueles que ela considerava que deveriam ser exibidos ou não.

A principal proposta, diante do objetivo da pesquisa, era possibilitar a produção de sentido, pela debatibilidade do tema, o que poderia permitir a ampliação do repertório comunicativo das participantes que apresentam defasagem de comunicação oral (produção) quando comparada à compreensão. 
Após a assinatura de Termo de Consentimento Livre e Esclarecido pelos professores e responsáveis das crianças, foi iniciada a coleta. Todas as atividades coletadas foram filmadas. Mais especificamente, utilizou-se o recurso da filmagem que é descrita por Meira (1995) como ferramenta importante para a investigação microgenética de processos psicológicos complexos, que permite capturar as ações comunicativas (orais e gestuais), importantes no presente estudo.

Dessa forma, aponta-se que algumas ações humanas ao melhor resgatadas pelo recurso da filmagem. Manzini (2001, p. 164) destaca que "na interação face-aface, o ser humano exibe uma infinidade de recursos verbais e não verbais que se misturam e se completam", que justifica o registro das situações por filmagens.

\subsection{UNIDADE DE ANÁliSE DO ESTUDO}

A estrutura central da unidade de análise do presente estudo é capturar a ocorrência das operações argumentativas (argumentos, contra-argumentos e respostas) nos discursos das participantes, adotando a unidade triádica do Leitão (2000b). Devido às especificidades comunicativas das participantes, os invariantes argumentativos podem surgir na forma dos elementos comunicativos das duas categorias, a saber:

1. Verbalizações: com construções verticais (um só elemento) ou com construções horizontais (mais de um elemento). Como os participantes do estudo têm características peculiares na comunicação, utiliza-se, aqui, tal descrição das verbalizações, com o propósito de capturar as operações argumentativas no discurso.

2. Gestos representativos (que sinalizam) a comunicação: podem ser formados por apontar, olhar, expressão facial, dentre outros, bem como o auxílio de símbolos gráficos. Como a proposta de atividade individual constituiu-se na elaboração de uma prancha em que apareciam alguns símbolos gráficos contemplou-se tais símbolos como forma de auxiliar a comunicação gestual.

Com as análises procurou-se identificar as características comunicativoargumentativas de crianças com síndrome de Down, propondo-se analisar a produção de sentidos favorecida pelo discurso argumentativo.

$\mathrm{Na}$ transcrição dos dados analisados, o sinal (+) indica pausas das participantes; parênteses duplos (( )) marcam comentários da pesquisadora; parêntese ( ) fala incompreensível. Os nomes das alunas apresentadas nas análises dos dados são fictícios, para que se possa cumprir com as exigências éticas da pesquisa.

Os recortes estão apresentados em turnos de fala em que há alternância entre as falas dos participantes da situação de aula (MARCUSCHI, 1999). Nos excertos apresentados na análise dos dados o (T) representa tais turnos com 
alternância entre os participantes. Contudo, isto não quer dizer que haja a utilização de todos os elementos da análise da conversação na transcrição dos dados.

\section{Resultados E discussão}

Para ilustrar o tratamento dispensado ao conjunto de dados gerados na pesquisa, as análises dos recortes dos protocolos das situações serão apresentadas a seguir. Ressalta-se que os excertos apresentados não se referem ao início da atividade, mas a partes das situações.

\section{Transcrição de Sara.}

Turma: $3^{\circ}$ ano do $1^{\circ} \mathrm{Ciclo}$

Assunto proposto: Merenda Escolar

A atividade, desenvolvida individualmente, teve como temática os alimentos da merenda escolar. Foi realizada com base em cartões que continham alimentos previamente selecionados pela pesquisadora. Foram criadas duas categorias de alimentos: (a) os que devem ter na merenda, por Sara gostar; (b) os que não devem ter na merenda. A aluna deveria colar na prancha as respectivas figuras, que foi subdividida com uma linha, utilizando dois símbolos que representavam o gostar e o não gostar.

T219 [Pesquisadora]: e batata frita? ((Sara levanta a cabeça enquanto cola a figura do quiabo e olha para a imagem da batata frita)).

T220 [Sara]: goto

T221 [Pesquisadora]: gosta?

T222 [Sara]: ((balança a cabeça afirmando))

T223 [Pesquisadora]: gosta mesmo? Tu acha que tem que ter na merenda ou não tem?

T224 [Sara]: teeeem.

T225 [Pesquisadora]: mas num faz mal pra saúde não?

T226 [Sara]: tem não ((ainda colando a imagem do quiabo))

T227 [Pesquisadora]: faz não mal?

T228 [Sara]: ao ((Sara termina de colar a imagem do quiabo)).

T229 [Pesquisadora]: num engorda? Faz mal ao coração da gente? ((pesquisadora encara com olhar questionador)).

T230 [Sara]: az ão.

T231 [Sara]: az ao.

T232 [Pesquisadora]: se comer muita batata frita?

T233 [Sara]: goto

T234 [Pesquisadora]: a pessoa morre.

T235 [Sara]: morre não. Vovô ai morre ((inconpreensível)) vovô morreu. Tinta

T236 [Pesquisadora]: trinta?

T237 [Sara]: ((balança a cabeça afirmando)) morreu

T238 [Pesquisadora]: ao se comer muita batata frita num fica gordo? ((faz movimento com os braços referindo-se as pessoas obesas))

T239 [Sara]: godo ((balança a cabeça afirmando))

T240 [Pesquisadora]: gordo, né? E é pra ter na merenda? 
T241 [Sara]: tem ((balança a cabeça afirmando mais de uma vez))

T242 [Pesquisadora]: vai fazer mal pras crianças.

T243 [Sara]: ((Sara observa, fica pensando e pega a imagem da bebida láctea de morango)). ai cooca esse qui.

T244 [Pesquisadora]: colocar esse. Esse é o que?

T245 [Sara]: ((olha para imagem)) none

T246 [Pesquisadora]: danone?

T247 [Sara]: ((balança a cabeça afirmando))

T248 [Pesquisadora]: é?

T249 [Sara]: eu oto none

T250 [Pesquisadora]: tu gosta?

T251 [Sara]: oto

T252 [Pesquisadora]: tem na merenda?

T253 [Sara]: tem ((olha pra imagem))

T254 [Pesquisadora]: tu acha que deve ter?

T255 [Sara]: tem ((balança a cabeça))

Inicialmente percebe-se que Sara desenvolve seu argumento com base na ideia de gostar ou não gostar de batata frita, introduzida por ela sem a intervenção da pesquisadora. Em T220, o ponto de vista de Sara (goto) aparece de forma verbalizada - construção vertical. Já em T222, Sara demonstra permanecer com o mesmo ponto de vista que aparece na forma de gesto (balança a cabeça com sinal de afirmação). Posteriormente, surge a temática ter ou não ter batata frita na merenda escolar, que está relacionada ao fato dela gostar de batata frita. Ela reafirma o ponto de vista em T224, com uma construção verbal vertical (teeem), que aparece enfaticamente. Após o contra-argumento da pesquisadora em T225 (mas não faz mal pra saúde não?) Sara parece mudar seu ponto de vista em T226, verbalizando em uma construção horizontal, com dois elementos (tem não). Parece haver aqui um processo de horizontalização do discurso - o que antes aparece na forma de construção verbal vertical e gestos surge, após a oposição da pesquisadora, em uma construção verbal horizontal. Como discutem Nunes (2003), as construções verbais horizontais indicam uma elaboração da oralidade que não é apresentada nas construções verbais verticais.

Na sequência, a pesquisadora insiste no contra-argumento de que batata frita faz mal para saúde, acrescentando alguns elementos em T229, mas não obtém sucesso, pois Sara permanece com o seu ponto de vista inicial, que aparece em T230 e T231. Em T234, a pesquisadora lança outro contra-argumento para tentar convencer a Sara de que batata frita faz mal para saúde (a pessoa morre). Sara, em T235, mantém parcialmente seu ponto de vista, por ele aparecer enfraquecido, pela relação contextual que ela faz com a morte do avô (Morre não. Vovô ai morre ((INCONPREENSÍVEL)) vovô morreu. Tinta). Ressalta-se que o ponto de vista de T235 apresenta-se na categoria verbalização com várias construções horizontais de dois elementos, inclusive, com elementos discursivos incompreensíveis, havendo um possível avanço discursivo, que parece ser permitido pelo processo discursivo da argumentação. Aqui se pode refletir acerca do papel da argumentação na 
produção e ampliação de sentidos (LEITÃO, 1999, 2000b, 2003), que é permitido pela construção discursiva entre pesquisadora e aluna.

Em T238, a pesquisadora apresenta outro contra-argumento para tentar convencer Sara a retirar a batata frita do suposto cardápio da merenda escolar (ao se comer muita batata frita num fica gordo?). Ela concorda (em T239) com o contraargumento da pesquisadora, contudo não muda seu ponto de vista de que deve ter batata frita na merenda escolar (em T241), que aparece na forma de construção vertical (tem) e gestos representativos (balança a cabeça afirmativamente). Em T242, a pesquisadora, apresenta um novo elemento ao seu contra-argumento (vai fazer mal para as crianças) que leva Sara ao abandono do tópico batata frita, ao desenvolver uma ação de pegar outra figura (iorgute) e verbalizar numa construção horizontal de quatro elementos (ai cooca esse qui). O fato dela desenvolver uma verbalização em uma construção horizontal com tantos elementos fortalece a ideia de possível abandono do tópico. Em T249, ela justifica a adesão ao ponto de vista de ter Danone (nome da bebida láctea de morango) na merenda escolar, com a verbalização horizontal (eu oto none).

Não se percebeu durante a situação entre pesquisadora e aluna com impedimentos na comunicação momentos que impedisse completamente o desenvolvimento da atividade discursiva. Mesmo com um das interlocutoras (Sara) com impedimentos comunicativos, foi possível apreender o diálogo e a negociação, marcadamente pela manutenção do argumento de Sara na presença dos contra-argumentos da pesquisadora, que acabaram por gerar o abandono do tópico por Sara.

O contra argumento parece exercer um papel crucial também em crianças com impedimentos na comunicação na medida em que permite a construção/ produção de sentidos, estudo de Cavalcante e De Chiaro (no prelo). Tal estudo menciona o favorecimento da produção de sentidos em cenário de sala de aula; a professora nessa situação exercer ações discursivas próprias da argumentação que possibilita a participação coletiva e a produção de sentidos de alunos que em outras práticas pedagógicas não participariam.

\section{Transcrição de Maria}

Turma: $2^{\circ}$ Ano do $1^{\circ}$ Ciclo (manhã)

Assunto Proposto: Programas de televisão

Os seguintes fragmentos da atividade transcrita tinham como objetivo montar juntamente com a participante (Maria) com síndrome de Down, uma prancha. Foram previamente selecionados programas de televisão que possivelmente fossem de interesse de Maria para que ela organizasse a prancha, ao escolher os programas que ela gosta e que não gosta. Assim, solicitamos que ela optasse e justificasse a sua escolha, para que houvesse a emergência do discurso argumentativo. 


\author{
Recorte \\ T246 [pesquisadora]: é! Isso! Gosta de Fantástico? \\ T247 [Maria]: Goto. \\ T248 [pesquisadora]: Fantástico? \\ T249 [Maria]: ((balança a cabeça dizendo que sim)) \\ T250 [pesquisadora]: tu vai dormir que horas? \\ T251 [Maria]: minha cama. \\ T252 [pesquisadora]: tua cama? \\ T253 [Maria]: embaixo. \\ T254 [pesquisadora]: embaixo? Tu dorme depois do Fantástico? \\ T255 [Maria]: Goto não. \\ T256 [pesquisadora]: Gosta não? Tu dorme com teu pai é? \\ T257: ((balança a cabeça dizendo que sim)). ((cantando e imitando o chaves)) Chaves, chaves.
}

Maria apresenta em T247 seu ponto de vista relativo ao programa de televisão denominado fantástico. Seu ponto de vista aparece em forma de construção verbal vertical - apenas um elemento (goto). Após solicitação da pesquisadora em T248 para que ela continue a discussão (fantástico), Maria em T249, permanece com o seu ponto de vista, que aparece por gestos representativos (balança a cabeça afirmativamente). O uso demasiado de gestos por Maria corrobora o que discute Porto-Cunha e Limongi (2008) ao apontarem que os indivíduos com síndrome de Down usam gestos como forma de superar o impedimento de produção oral. Além disso, percebe-se que até o T248 a participante não utiliza muitos operadores argumentativos, apresentando apenas ponto de vista. Para Leitão (1999, 2003), a justificação e o contra-argumento criam um espaço de negociação, gerando construções discursivas como a formulação, revisão e transformação.

Quando em T250, a pesquisadora questiona Maria sobre a possibilidade dela assistir um programa para adultos e que é exibido à noite (tu vai dormir que horas?), Maria aparenta realizar uma mudança de tópico em T251 (minha cama), relacionada à pergunta da pesquisadora, que aparece formulada com uma verbalização em construção horizontal (minha cama). No turno 251, a participante elabora uma construção verbal horizontal, o que sugere uma maior elaboração discursiva (NUNES, 2003).

Em T255 Maria retira seu ponto de vista, dizendo que não gosta do programa e verbaliza com a construção horizontal com dois elementos (goto não).

Em T257, Maria mantém seu ponto de vista relacionado a não gostar do programa fantástico e verbaliza Chaves, Chaves. Chaves foi um tema apresentado anteriormente e que Maria demonstrou ter muito interesse. Anteriormente, parecia ser o único programa que de fato ela gostava. Ressalta-se que ela retoma várias vezes como se apontasse: o único programa de televisão que eu gosto é o Chaves, que indica a manutenção do seu ponto de vista, mesmo após a tentativa da pesquisadora, com contra argumentos, de introduzir outros programas de televisão. Enfatiza-se, ainda, que Maria utilizava muitos gestos representativos durante toda a atividade. 
Verifica-se que existem diferenças individuais marcantes no discurso das participantes. Sara é mais comunicativa e utiliza mais elementos linguísticos verbais e não verbais; já Maria apresenta mais impedimentos de comunicação. Tais características remetem a necessidade de se pensar nas diferenças individuais das pessoas, com destaque para o ambiente educacional.

No caso da comunicação alternativa, a literatura aponta que para cada indivíduo é preciso que se tenham recursos de comunicação específicos e personalizados, para que seja possível atender as peculiaridades dos usuários (CAPOVILLA, 2001; MANZINI, 2001; TETZCHNER; MARTINSEN, 2000).

\section{CONSIDERAÇõES FINAIS}

Ressalta-se que os impedimentos na comunicação em decorrência da síndrome de Down aparecem nos recortes dos protocolos das situações realizadas individualmente entre as alunas e a pesquisadora. As crianças investigadas desenvolvem a comunicação, em sua maioria, com construções verbais verticais (com um só elemento) e com gestos. Nos indivíduos com síndrome de Down, os gestos são tomados como forma discursiva de primeira ordem e as verbalizações são desenvolvidas como forma de comunicação auxiliar (secundária).

Mesmo com tais impedimentos, as crianças participantes da pesquisa apresentam elementos argumentativos em seu discurso (argumento e contra argumentos), havendo maior ocorrência de argumentos (pontos de vista e justificativa). O discurso das duas alunas caracteriza-se pelo uso mais frequente de construções verticaise gestos, comumem criançascomimpedimentoscomunicativos (PORTO-CUNHA; LIMONGI, 2008; TETZCHNER; MARTINSEN, 2000). As situações ilustradas sugerem que, mesmo sem uma fluente comunicação verbal, as pessoas com síndrome de Down desempenham suas funções comunicativas, demonstrando que é preciso valorizar todas as formas de comunicação, conforme destaca Omote (2001).

Nesta direção, as ferramentas de Comunicação Alternativa e Aumentativa são recursos auxiliares importantes para que haja acessibilidade cognitiva das pessoas com impedimentos comunicativos, na medida em que permitirão uma maior estimulação por parte dos adultos que convivem com a criança - familiares e educadores.

Observa-se que crianças investigadas parecem se favorecer do uso de ferramentas de comunicação alternativa, mesmo que não as utilizem no seu cotidiano escolar, familiar e social. Nesse sentido, Manzini (2001), ao descrever os usuários, apresentam as pessoas com síndrome de Down como se favorecendo do sistema de comunicação alternativa com figuras.

Acredita-se que a argumentação, como já discutido por Cavalcante e Santa-Clara (no prelo), pode ser utilizada como um artefato discursivo importante 
para que haja o desenvolvimento da comunicação e incentivo da verbalização em pessoas com impedimentos na comunicação, na medida em que a argumentação permite a instauração e mobilização de ações/produções discursivas, bem como pode favorecer a construção de conhecimento, como destaca Leitão (2000a).

\section{REFERÊNCIAS}

CAPOVILLA, F. C. Comunicação alternativa: modelos teóricos e tecnológicos, filosofia educacional e prática clínica. In: K. CARRARA (Org.). Educação, universidade e pesquisa. São Paulo: FAPESP, 2001.

CAVALCANTE, T.C.F.; SANTA-CLARA, A. Acessibilidade comunicativa de pessoas com síndrome de down através de atividades argumentativas. In: MOUTINHO, K.; VILLACHAN-LYRA, P.; SANTA-CLARA, A. (Org.). Novas tendências em psicologia do desenvolvimento: Teoria, Pesquisa e Intervenção. Recife: FASE editora (no prelo).

CAVALCANTE, T.C.F.; DE CHIARO, S.R. Acessibilidade de indivíduos com síndrome de Down: argumentação em sala de aula (no prelo).

CONVENÇÃO SOBRE OS DIREITOS DA PESSOA COM DEFICIÊNCIA. Nova Iorque, 2006.

DE CHIARO, S.; LEITÃO, S. O papel do professor na construção discursiva da argumentação em sala de aula. Psicologia: Reflexão e Crítica, Porto Alegre, v.18, n.3, p.350357, 2005.

FERREIRA, D. R. S. A.; FERREIRA, W. A.; OLIVEIRA, M. S. Pensamento e linguagem em crianças com síndrome de Down: um estudo de caso da concepção das professoras. Ciências \& Cognição, Rio de Janeiro, v.15, n.2, p.216-227, 2010.

PINTO, G. U. GÓES, M. C. R. Deficiência mental, imaginação e mediação social: um estudo sobre o brincar. Revista Brasileira de Educação Especial, Marília, v.12, n.1, p.11-28, 2006.

MARCUSCHI, L. A. Análise da conversação. São Paulo: Ática, 1999.

LEITÃO, S. Contribuições dos estudos contemporâneos da argumentação a uma análise psicológica de processos de construção de conhecimento em sala de aula. Arquivos brasileiros de psicologia, Rio de Janeiro, v.51, n.1, p.91-109, 1999.

. A construção discursiva da argumentação em sala de aula. In: REUNIÃO ANUAL DA SOCIEDADE BRASILEIRA DE PSICOLOGIA, 30., Brasília, 2000a. Resumos... Brasília, p.15. $360,2000 \mathrm{~b}$.

. The potential of argument in knowledge building. Human Development, n.6, p.332-

. Argumentação como processo de construção do conhecimento. In: ENCONTRO INTERNACIONAL LINGUAGEM, CULTURA E COGNIÇÃO, 2., Belo Horizonte, 2003. Anais do Encontro Internacional Linguagem, Cultura e Cognição - Reflexões para o ensino... Campinas, 2003. 
LIMONGI, S. C. O. Linguagem na Síndrome de Down. In: FERREIRA, L. P.; BEFI-LOPES, D. M.; LIMONGI, S. C. O. (Org.). Tratado de Fonoaudiologia. São Paulo: Editora Roca Ltda, 2004. p.954-966.

MANZINI, E. J. Conceitos básicos em comunicação alternativa e suplementar. In: CARRARA, K. (Org.). Educação, universidade e pesquisa. São Paulo: FAPESP, 2001.

MEIRA, L. Análise microgenética e videografia: ferramentas de pesquisa em psicologia cognitiva. Temas em Psicologia, v.1, n.3, p.59-71, 1995.

NUNES, L. R. O. P. Modelos teóricos na comunicação alternativa e ampliada. In: NUNES, L. R. O. P. (Org.). Favorecendo o desenvolvimento da comunicação em crianças e jovens com necessidades educacionais especiais. Rio de Janeiro: Dunya, 2003.

OMOTE, S. Comunicação e relações interpessoais. In: CARRARA K. (Org.). Educação, Universidade e Pesquisa. São Paulo: FAPESP, 2001.

PAULA, K. M. P.; ENUMO, S. R. F. Avaliação assistiva e comunicação alternativa: procedimentos para a educação inclusiva. Revista Brasileira de Educação Especial, Marília, v.13, n.1, p.3-26, 2007.

PORTO-CUNHA E.; LIMOGI, S.C.O. Modo comunicativo utilizado por crianças com síndrome de Down. Pró-Fono Revista de Atualização Científica, São Paulo, v.20, n.4, p.243248, 2008.

PUESCHEL, S. M. (Org.). Síndrome de Down: guia para pais e educadores. 11. ed. São Paulo: Papirus, 2006.

SILVA, M. F. M. C.; KLEINHANS, A. C. S. Processos cognitivos e plasticidade cerebral na Síndrome de Down. Rev. Brasileira de Educação Especial, Marília, v.12, n.1, p.123-138, 2006.

STRAY-GUNDERSEIN, K. Crianças com Síndrome de Down: guia para pais e educadores. 2 ed. Porto Alegre: Artmed, 2007.

TETZCHNER, S. V.; MARTINSEN, H. Introdução à comunicação aumentativa e alternativa. Porto: Porto editora, 2000.

VOIVODIC, M. A. M. A. Inclusão escolar de crianças com Síndrome de Down. Petrópolis: Vozes, 2004.

Recebido em: 16/02/2011

Reformulado em: 22/08/2011

Aprovado em: 14/10/2011 